\title{
Correction to: Socio-legal systems and implementation of the Nash solution in Debreu-Hurwicz equilibrium
}

\author{
Claus-Jochen Haake ${ }^{1}$ (D) $\cdot$ Walter Trockel $^{2}$ (D
}

(c) Springer-Verlag GmbH Germany, part of Springer Nature 2022

\section{Correction to: Review of Economic Design https://doi.org/10.1007/s10058-021-00278-z}

In definition 1, the expression in (iii) was incorrectly typeset. It should have read as

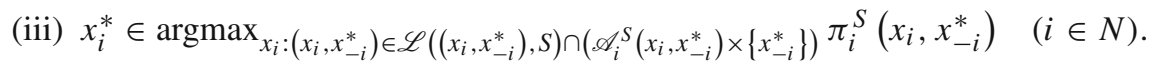

The original article has been corrected.

Publisher's Note Springer Nature remains neutral with regard to jurisdictional claims in published maps and institutional affiliations.

The original article can be found online at https://doi.org/10.1007/s10058-021-00278-z.

$\varangle$ Claus-Jochen Haake cjhaake@wiwi.upb.de

Walter Trockel

walter.trockel@uni-bielefeld.de

1 Paderborn University, Paderborn, Germany

2 Bielefeld University, Bielefeld, Germany 